\title{
Role of Mn-oxides in regulating fate and transport of soil organic matter
}

\author{
HuI LI ${ }^{1}$, ElizABETH HERNDON ${ }^{2}$
}

${ }^{1}$ Earth Sciences Group, Environmental Sciences Division, Oak Ridge National Laboratory, Oak Ridge, TN 37831; lih4@ornl.gov

${ }^{2}$ Earth Sciences Group, Environmental Sciences Division, Oak Ridge National Laboratory, Oak Ridge, TN 37831; herndonem@ornl.gov

Soil is the largest terrestrial carbon (C) reservoir and contains more $\mathrm{C}$ than vegetation and the atmosphere combined. Much of this soil $\mathrm{C}$ is intimately asscociated with minerals. Most past studies have largely focused on influences of $\mathrm{Fe}$ - and $\mathrm{Al}$-(hydr)oxides in stabilizing and transforming soil organic carbon (SOC), whereas, the importance of Mn-oxides in controlling fate and transport of soil organic carbon has been relatively understudied. Manganese $(\mathrm{Mn})$, as an essential trace metal with strong redox potential, may play a significant role in regulating $\mathrm{C}$ cycling in soils by adsorbing or oxidizing organic compounds.

In the present study, the affinity of seven aromatic and nonaromatic organic compounds for common soil Mn-oxides in nature is examined. Three Mn-oxides comprised of layer or tunnel structures are specifically studied. Effects of Mn-oxide crystallinity and crystal structure and of environmental $\mathrm{pH}$ conditions on $\mathrm{Mn}-\mathrm{OC}$ interaction mechanisms are investigated in depth. We hypothesize that different Mnoxides possess different sorption and/or oxidation capacities and variation in binding mechanisms of different OC compounds under different $\mathrm{pH}$ conditions. Under near neutral $\mathrm{pH}$, we expect phthalate and propanol to primarily sorb on Mn-oxides, rather than reduce Mn-oxides via redox reactions. However, organic compounds such as catechol, ascorbate, hydroquinone, pyruvate and citrate are expected to dissolve appreciable amounts of Mn-oxides through ligand-promoted or reductive dissolution. X-ray diffraction (XRD), BrunauerEmmett-Teller (BET) analysis and transmission electron microscopy (TEM) are utilized to determine the identity as well as crystallinity of minerals. Total organic carbon (TOC) analyzer and inductively coupled plasma mass spectrometry (ICP-MS) are applied to monitor transport and transformation of OC and metal dissolution. In addition, infrared (IR) spectroscopy is used to provide binding information between Mn-oxides and OC. Together, these results will provide more detailed fundamental insights into reactions happening at organo-mineral interfaces in soils. 